\title{
Social network addiction and advertising
on social networks: A case study of rural \\ Social network addiction and advertising
on social networks: A case study of rural students in South Africa
}

\begin{tabular}{|c|c|}
\hline \multicolumn{2}{|c|}{$\begin{array}{l}\text { Authors: } \\
\text { Zhikona van Rhyne }{ }^{1} \text { @ } \\
\text { Willie Chinyamurindi }{ }^{1} \text { — } \\
\text { Liezel Cilliers }{ }^{2} \text { — }\end{array}$} \\
\hline \multicolumn{2}{|c|}{$\begin{array}{l}\text { Affiliations: } \\
\text { 'Department of Business } \\
\text { Management, University } \\
\text { of Fort Hare, East London, } \\
\text { South Africa }\end{array}$} \\
\hline \multicolumn{2}{|c|}{$\begin{array}{l}{ }^{2} \text { Department of Information } \\
\text { Systems, University of } \\
\text { Fort Hare, East London, } \\
\text { South Africa }\end{array}$} \\
\hline \multicolumn{2}{|c|}{$\begin{array}{l}\text { Corresponding author: } \\
\text { Liezel Cilliers, } \\
\text { Icilliers@ufh.ac.za }\end{array}$} \\
\hline \multicolumn{2}{|c|}{$\begin{array}{l}\text { Dates: } \\
\text { Received: } 18 \text { Feb. } 2019 \\
\text { Accepted: } 29 \text { Apr. } 2019 \\
\text { Published: } 29 \text { July } 2019\end{array}$} \\
\hline \multicolumn{2}{|c|}{$\begin{array}{l}\text { How to cite this article: } \\
\text { Van Rhyne, Z., Chinyamurindi, W. } \\
\text { \& Cilliers, L., 2019, 'Social } \\
\text { network addiction and } \\
\text { advertising on social } \\
\text { networks: A case study of } \\
\text { rural students in South } \\
\text { Africa', South African Journal } \\
\text { of Information Management } \\
21(1) \text {, a1081. https://doi.org/ } \\
\text { 10.4102/sajim.v21i1.1081 }\end{array}$} \\
\hline \multicolumn{2}{|c|}{$\begin{array}{l}\text { Copyright: } \\
\text { (C) 2019. The Authors. } \\
\text { Licensee: AOSIS. This } \\
\text { is licensed under the } \\
\text { Creative Commons } \\
\text { Attribution License. }\end{array}$} \\
\hline \multicolumn{2}{|l|}{ Read online: } \\
\hline 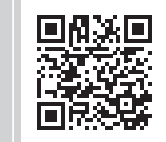 & $\begin{array}{l}\text { Scan this QR } \\
\text { code with your } \\
\text { smart phone or } \\
\text { mobile device } \\
\text { to read online. }\end{array}$ \\
\hline
\end{tabular}

Background: There is growing evidence that social media addiction is an enduring problem among students. This information can be used by marketers to create specific advertisement campaigns for students to promote organisational branding.

Objectives: The aim of this study was to determine the mediating role of psychological dependence between social networking sites (SNSs) addiction and attitude towards social networking advertising among a sample of rural students in South Africa.

Method: This research adopted a positivist paradigm with a quantitative approach and a descriptive research design. Data were collected using questionnaires, which were distributed to 289 respondents residing within a rural community in the Eastern Cape province of South Africa.

Results: This study found a relationship between: (1) perceived ease of use and habit, (2) perceived ease of use and psychological dependence, and (3) psychological dependence and attitude towards SNSs advertisement.

Conclusion: Social media advertising should offer precise location-based targeting and datadriven users' profiling, segmenting the target market according to preferences, likes and hobbies, through data mining and analytical interpretation of results as these are attributes that are not offered by traditional media.

Keywords: psychological dependence; social networking sites; habit; ease of use; social networking advertising.

\section{Introduction}

There are 31 million people in South Africa who are currently using the Internet, of which $79 \%$ are estimated to be university students (Lin \& Wang 2017). The ubiquitous nature of social media means that it is trendy among students, as they can access the Internet on various devices whenever and wherever they want (Marino et al. 2018).

Cao et al. (2008) observed that most students own a mobile device and have access to the Internet. In addition, students spend approximately $8 \mathrm{~h}$ a day on social media. Checking and posting on social networking sites (SNSs) has become a habit for young adults, such as students, because of consistent access, use and continuous interaction. Social networking sites can be used to improve formal learning purposes, but may cause a distraction during class time. The students make use of social media to access information for academic purposes and communicate with lecturers via email (Lau \& Lee 2018).

In contrast to the usage of social media for learning purposes, students use SNSs such as Facebook, Instagram, Twitter and YouTube for entertainment purposes, which may cause a student to neglect important activities (Yang, Wang \& Lee 2016). Young adults are considered to be digital natives because they have been surrounded by computers, laptops, mobile phones and the Internet since birth (Farhangpour \& Matendawafa 2016). The perceived ease of use of these devices has led to approximately $70 \%$ of students admitting that they make use of mobile phones during class times (Lin \& Wang 2017; Moqbel \& Kock 2017; Shava \& Chinyamurindi 2018). However, the students also admit that they lose track of time and delay tasks they intend to get done such as term papers and preparing for final examinations (Meier, Reinecke \& Meltzer 2016). 
Muwanga-Zake and Herselman (2017) highlight that students who do not have access to SNSs become socially excluded that threatens an individual's essential psychological need such as belonging and self-esteem. Das (2014) mentioned that individuals live between two worlds, which is identified as our physical selves and cyberspace. He elaborated by saying that these two worlds remain uncontested as they are parallel but disjointed. 'With the proliferation of digital technologies in our everyday lives and the increased usage of networking sites, these two realms will slowly converge into one another' (Das 2014:34).

Social networking sites addiction can be defined as 'a psychological dependence on the use of SNSs that interferes with other essential activities and yields negative consequences' (Moqbel \& Kock 2017:109). The excessive use of SNSs may be seen as a behavioural addiction because it shares several features with other types of addiction such as withdrawal, tolerance, relapse, conflict and mood modification (Griffiths 2005). Internet addiction is a passive coping mechanism with users relying on the Internet to escape from real-life problems and troubling feelings. If users make use of negative coping strategies, it may lead to a decrease in their overall well-being (Giunchiglia et al. 2017; Omar, Dahalan \& Yusoff 2016). Therefore, it is reasonable that SNSs addiction could lead to several negative outcomes such as depression, preoccupation or loss of interest in activities, social retreat, intolerance, withdrawal and loss of control (Muller et al. 2015). Organisations that make use of SNSs for advertisement purposes have now started to take note of this addiction among the youth to target their social media marketing activities. The benefits from these online marketing activities for organisations include to improve social network salience, enhance interest and build relationships with the online public (Parveen, Jaafer \& Anin 2014; Shava \& Chinyamurindi 2018). Social media advertising emerged as an attractive vehicle for augmenting advertising effectiveness as it is relatively cheap and can reach a wide audience. In addition, marketing activities can easily be scaled up to various contexts and cultures. Henceforth, social media advertising is a form of online advertising that focuses on social networking services. Advertising, word of mouth (WOM), customer relationship management and branding are some marketing practices that organisations worldwide have adopted to build a profitable marketing relationship (Alawan 2018; Omar, Dahalan \& Yusoff 2016). Companies now make use of social media advertising to generate and deliver marketing communication through comments, sharing and other functions in an ubiquitous and accessible way (Alalwan et al. 2017).

Based on the literature above, the research question proposed in this study is as follows: How does psychological dependence on SNSs influence the attitude towards social networking advertising among a sample of rural students in South Africa? The remainder of the article is organised as follows. A literature review introduces the theoretical literature and hypotheses formulated for the study; the research design and methodology; the results of the empirical analysis, discussion and the conclusion; and recommendations for theory and practice.

\section{Literature review}

Social media refers to 'websites and applications that are designed to allow people to share content quickly, efficiently, and in real-time' (Hajarian et al. 2017:283). Studies and work revealed that social media is exceeding interactive platforms that apply and engage mobile devices and other web-based technologies to facilitate individuals, groups and communities in developing, sharing and discussing the content produced by the user (Hajarian et al. 2017; Matikiti, Mpinganjira \& Roberts-Lombard 2017).

\section{Theoretical literature}

To understand the nature of social media usage among students in South Africa, two theories called Media Dependency Theory (MDT) and the Theory of Reasoned Action (TRA) will be discussed in this section.

Sandra Ball-Rokeach and Melvin DeFleur introduced MDT in 1976. The theory is a systematic approach to the study of the effects of mass media on audiences. The theory also investigates the interactions between media, audiences and social systems (Carillo, Scornavacca \& Za 2017). Furthermore, dependency theory conceives of dependency as a relationship in which the fulfilment of one need must be fulfilled by frequent visits on social media (Lin 2008). The main focus of the theory is the relationship between media and the audience, for example, students. Individuals living in information-based societies tend to develop a dependency on media to satisfy a variety of their needs (Lee \& Choi 2018). Ball-Rokeach and DeFleur put forward that if the actions performed for an audience by a medium is beneficial, the audience's dependency on that medium will increase. Also, the higher the instability of a society, the higher the audience's dependency on the media for information, which translate in a greater potential for the media to influence the audience (Lin 2008).

There are potentially three types of effects that result from an audience's dependency on the media: cognitive, affective and behavioural. Cognitive effects are changes in an audience's attitudes, beliefs and values, including changes, brought about by the media in its role. Affective effects include the development of feelings of fear and anxiety, and an example of a behavioural effect is deactivation, which occurs when individual members of an audience refrain from taking specific actions that they would have taken, had they not been exposed to individual messages from the media (Lee \& Choi 2018; Li 2014). The MDT further suggested that people became more dependent on media, the influence of media on their perceptions and behaviours become stronger, as it points out that their dependency on social media changes as their environment and goals change (Carillo et al. 2017). That is, when their dependency on media changes, so does 
the structure of the whole dependency system. Thus, media dependency is not a one-way monolithic process. Rather it is an interdependent relationship between the people, media and social system (Lee \& Choi 2018).

Ajzen and Fishbein (1981) state that the TRA was first introduced in 1967 by Martin Fishbein to understand the relationship between attitude and behaviour. It was born out of the frustration resulting from repeated failure to predict behaviour from traditional measures of attitude. The TRA was based on the assumption that human beings are rational and make systematic use of available information, although people consider the implications of their actions before they decide whether to perform a given behaviour. The TRA attempts to explain the relationship between beliefs, attitudes, intentions and behaviour (Beadnell et al. 2008; Tlou 2009; Trafimow \& Lench 2015). Individuals' attitudes towards behaviour and subjective norms are the fundamental factors towards behavioural intention. Therefore, TRA consists of three conditions in which intention of an individual can accurately predict behaviour (Aleassa, Pearson \& McClurg 2011). Also, the TRA focused on the role of subjective norms and attitudes towards behaviour to predict behavioural intentions (Trafimow \& Lench 2015). It aimed to explain the relationship between attitudes and behaviour within human action and is used to predict how individuals will behave based on their pre-existing attitudes and behavioural intentions (Southey 2011). Firstly, the intention and behaviour measures correspond to the specificity of action, target, context and time frame. Secondly, intention and behaviour do not change in the interval between assessment of intention and assessment behaviour. Finally, the behaviour in question is under the individual's volitional control that he or she can decide at will to or not perform (Fishbein \& Ajzen 2005). However, under circumstances where internal and external factors may hinder the volitional control of behaviour, the TRA is a poor predictor of these types of behaviour (Tlou 2009). This theory has since been developed, and it has been used successfully to predict and understand human behaviour (Sanne \& Wiese 2018). In this study, the researcher has given an explanation detailing the habitual use of SNSs that led up to psychological dependence, as well as SNSs addiction and attitude towards social networking advertising.

The following section outlines existing empirical literature and hypotheses of the study.

Hamid et al. (2016) affirmed perceived ease of use as the degree to which an innovation is perceived not to be difficult to understand, learn or operate, which led to learned behaviours that evolve into repeated behaviour without conscious intention. A habit was defined as the extent to which a regular tendency or practice that is hard to give up. Habits can be viewed from the perspective of a reflexive system where behavioural schemata are formed from repeated past experiences to keep track of cognitive, affective and behavioural responses to specific actions (Amoroso \& Lim 2017; Osatuyi \& Turel 2018; Wood \& Runger 2015). Saade and Kira (2017) mention that stored behavioural schemata or cognitive structures are connected through associative processes when similar actions are encountered in future. The process of recalling stored behavioural schemata occurs spontaneously, making it seem automatic without engaging long-term memory or serial processing of information (Hansen, Saridakis \& Benson 2017). This means that as the students use SNSs repeatedly, their brain develop a cognitive structure of triggers and actions that surround the use of behaviours and associated responses. For instance, if the student checks his or her Facebook profile each time he or she receives a notification from Facebook and learns that this is enjoyable, then over time the student would have formed the habit of checking every notification that is received from Facebook. Consequently, the student will automatically check his or her Facebook profile the next time a notification comes in without paying any regard to the appropriateness of the action (Ashraf, Thongpapani \& Spyropoulou 2016). The checking of notifications in social media started as an activity that required no effort in doing, then became a regular tendency. Therefore, it can be expected that:

H1: There is a positive relationship between perceived ease of use and habit

Perceived ease of use has been defined in several ways. Hamid et al. (2016) defined perceived ease of use as the degree to which a person believes that using technology will be free from effort. In the context of this study, perceived ease of use refers to the extent to which students have found it easy to understand and use social media to the point it has become a habit. However, such a seemingly constant connection could be problematic because of empirical findings that excessive use leads to addiction followed by envy, depression and anxiety (Marino et al. 2018). Consequently, addiction is a public health concern as users' experience compulsive use, withdrawal, negative consequence, mood alteration, salience, tolerance and relapse, which resulted from the preference for online social interaction (Yu et al. 2017). Recent studies have provided initial evidence that these factors contribute to social media addiction because a preference for online interactions is positively associated with excessive ease of use of SNSs (Liu \& Ma 2018). It can be expected that a person who owns a smartphone that has SNSs on their mobile phone will frequently visit their social media platforms whenever they have a sudden urge to go online, as having access to social media and logging in is an impulsive activity that is carried out throughout the day (Hung, Tsai \& Chou 2016). Moreover, a person who is strong on innovativeness is a reflection of open-mindedness to new applications, and becomes very easy for them to be dependent on SNSs (Yahia, Al-Neama \& Kerbache 2018). Therefore, having an addictive personality and an easy activity may result in a psychologically dependent user. Based on all of this, it can be expected that:

H2: There is a positive relationship between perceived ease of use and psychological dependence

Social media first became an option for marketers back in 2005, when Facebook launched its first advertising plan. 
Since then SNSs have advanced in leaps and bounds, offering a reasonably low-cost advertising option to marketers, as well as the opportunity to reach a wide audience cheaply as long as the advertisements are engaging enough (Shareef et al. 2017). The advertising literature defined attitude towards advertising as a predisposition to respond favourably or unfavourably to a particular advertising stimulus during a particular exposure occasion, so the attitude towards an advertising concept specifically addresses the evaluations of a given advertisement (Ohajionu \& Mathews 2015). According to Kuss and Griffths (2011), the attention span of an individual lasts approximately $3 \mathrm{~s}$, and it is, thus, crucial for marketers to ensure that they capture the students' attention immediately. The strategies advertisers use are catchy phrases or jingles that surprise the student and turn their attention to purchase behaviour (Shareef et al. 2017). The advertisement must create a buzz that will get students talking, which leads to others wanting to view that advertisement in case they are missing out (Hadija, Barnes \& Hair 2012). The following hypothesis was formulated to test this construct:

H3: There is a positive relationship between psychological dependence and attitude towards SNSs advertisement

\section{Research methodology Research design}

The study was informed by a positivist paradigm and adopted a descriptive research design to observe a phenomenon and explore correlations between two entities (Kyeyune 2010). Specifically, the study utilised a questionnaire to gather selfreported data from students in a relatively short time.

\section{Population and sample}

The target population of this study was a sample of rural students in South Africa who reside within the Eastern Cape province, Amothole District, in a small town called Alice. A convenience sampling method was used to distribute the questionnaires. In total, 289 questionnaires were returned, which according to the Raosoft calculator (confidence level $95 \%$ and margin of error $5 \%$ ) is large enough to produce a representative sample.

\section{Measuring instrument}

A questionnaire consisting of two sections was utilised for data collection. Section A items concerned demographic information, while section B had Likert scale items with scores ranging from 1 (strongly disagree) to 5 (strongly agree).

\section{Reliability and validity measures}

The internal consistency of the measuring instrument used in the current study was established using the Cronbach's alpha test. The Cronbach's alphas were calculated for the five scales and found to be acceptable in both cases, as shown in Table 1. The outcomes are presented in Table 1.
Nunnally (1978) and Pallant (2016) state that values of 0.70 and above represent a good level of reliability, whereas values between 0.50 and 0.69 are considered to indicate an acceptable level of reliability. Table 1 shows that the majority of the scales such as psychological dependence, SNSs addiction, attitude towards social networking advertisement and perceived ease of use utilised in this study have good reliability, while the scale habit had acceptable reliability.

\section{Data analysis}

The results of the demographics are presented in the ensuing discussion.

Table 2 revealed the demographic details of the participants of the study. The gender with the most frequency comprises female students with $54 \%$ and male students with $46 \%$. The age group of 20-30-years category was the majority group utilising social media, represented by $57.8 \%$, followed by the below 20-year age group category; however, the 41-50-year age group category was the least represented at $7 \%$. The majority of students who have access to social media were Africans with $81.7 \%$, with Xhosa-speaking students in the lead as the most frequent social media users at $69.9 \%$, as this study was undertaken in a Xhosadominated province.

Table 3 provided the results from the Pearson correlation test that was conducted for the various hypotheses. From the

TABLE 1: Reliability of test results.

\begin{tabular}{lc}
\hline Variable & Cronbach's coefficient \\
\hline Psychological dependence & 0.763 \\
Social networking sites addiction & 0.797 \\
Attitude towards SNSs advertisement & 0.866 \\
Perceived ease of use & 0.809 \\
Habit & 0.643 \\
\hline
\end{tabular}

SNSs, social networking sites.

TABLE 2: Demographics of respondents.

\begin{tabular}{llc}
\hline Variable & Category & $\mathbf{\%}$ \\
\hline Gender & Male & 46.0 \\
Age & Female & 540 \\
& Below 20 years: & 28.4 \\
& 20-30 years & 57.8 \\
& 31-40 years & 11.4 \\
Home language & 41-50 years & 2.4 \\
& Zulu & 13.5 \\
& English & 9.0 \\
& Afrikaans & 7.6 \\
& Other & 69.9 \\
\hline
\end{tabular}

TABLE 3: Correlation test result.

\begin{tabular}{llcccc}
\hline Construct & Description & $\begin{array}{c}\text { Perceived } \\
\text { ease of } \\
\text { use }\end{array}$ & Habit & $\begin{array}{c}\text { Psychological } \\
\text { dependence }\end{array}$ & $\begin{array}{c}\text { Attitude } \\
\text { towards SNSs } \\
\text { advertisement }\end{array}$ \\
\hline Perceived & Pearson correlation & 1 & 0.226 & -0.116 & 0.354 \\
ease of use & Sig. (2-tailed) & - & $0.000^{* *}$ & $0.048^{*}$ & $0.000^{* *}$ \\
& $N$ & 289 & 289 & 289 & 289 \\
\hline
\end{tabular}

*, Correlation is significant at the 0.05 level (2-tailed); **, correlation is significant at the 0.01 level (2-tailed).

SNSs, social networking sites. 
results, it is clear that the first and third hypotheses were significant with a $p$-value of 0.000 , while the second hypothesis was significant with a $p<0.05$ level. Therefore, evidence support that perceived ease of use leads to habit. It can be expected that the more students find social media easy to use, the more the technology will become a habit and there is a chance that they can develop a psychological dependence on social media. Lastly, there was evidence that supported that psychological dependence had an impact on student's attitude towards SNSs advertisement.

\section{Ethical considerations}

The research complied with regulations stipulated by the University Research Ethics Committee (UREC).

\section{Discussion}

The research sought to determine a relationship among perceived ease of use, habit, psychological dependence and attitude towards SNSs advertisement. The outcomes revealed positive and significant correlations between perceived use of use and habit; perceived ease of use and psychological dependence; and psychological dependence and attitude towards SNSs advertisement.

The research sought to determine a relationship between perceived ease of use and habit. From the literature, it was suggested that there might be a relationship between perceived ease of use of SNSs and habit of students. To deduce whether there was a correlation between perceived ease of use and habit, the Pearson correlation coefficient was performed, which indicated that there was a significant relationship present.

These results were similar to those reported by Hamid et al. (2016) that perceived ease of use of SNSs leads to behaviour that is automatic and becomes a habit (Yang et al. 2016). Hsiao, Chang and Tang (2016) posited that habit has a relationship with perceived ease of use that leads to psychological dependence. The reason for this is that the behaviour, in this case, students making use of SNSs, leads to satisfactory experiences that, in turn, will reinforce the behaviour until a certain level of fulfilment has been acquired. For instance, students who check SNSs every time a notification is delivered on their mobile phone and finds that this action is enjoyable will automatically check their SNSs the next time a notification comes through without any regard to the appropriateness of the action (Ashraf et al. 2016). The empirical results provided in the previous section concluded that $\mathrm{H} 1$ could be accepted as true.

The current study investigated the relationship between perceived ease of use and psychological dependence. The significant result provided in Table 3 provides sufficient evidence to conclude that perceived ease of use positively supports psychological dependence. These results corroborate findings of a study conducted by Yu et al. (2017) that provided evidence that online interactions are positively associated with perceived ease of use of SNSs. Hung et al. (2016) support the relationship between perceived ease of use of SNS and psychological dependence, which manifest in an impulsive activity that is carried out throughout the day. It has also been reported by Bailey, Bonified and Arias (2018) that many users constantly refresh their social media page for new tweets, as it is easy to do so. Individuals may even spend most of the day on SNSs while providing reasonable excuses for such a loss of self-control.

The objective of the study was to determine the relationship between psychological dependence, SNSs addiction and attitude towards social networking advertising among a sample of rural students in South Africa. To achieve this relationship, a Pearson correlation test was performed. From the results in Table 3, it was concluded that psychological dependence has a significant relationship on attitude towards SNSs advertisement.

Results of the current study share similarities with the previous research carried out by Hadija et al. (2012), in which individuals went online constantly as they feared they would miss out on important information or opportunities to participate in brand advertisements or competitions.

As the SNSs proliferate, the potential exists for this mental health problem to become worse to the point where there is neglect of personal life and activities among the student body (Kuss \& Griffths 2011). Therefore, there is sufficient evidence supporting the hypothesis that psychological dependence can have an impact on an individual's attitude towards SNS advertisement. In the same view, Shareef et al. (2017) maintain the relationship between psychological dependence and attitude towards SNS advertisement by stating that on social media, like any communication platform, advertisements are vital as it produces the link between a company brand and students visiting the SNSs. The advertisement receives exposure on the SNSs, and students can share the information with their friends and thus create a buzz around the brand. Therefore, SNSs advertising can be used to create word of mouth through psychologically dependent individuals who have made a habit of checking their SNSs frequently.

\section{Conclusions and managerial implications Theoretical implications}

The most significant theoretical contribution of this study is that there is a relationship between behaviour and attitude (Ajzen \& Fishbein 1981). Behaviour is how a natural phenomenon works or functions such as perceived ease of use, habit and psychological dependence, and attitude is a settled way of thinking or feeling about something such as attitude towards SNSs advertisement. These are the factors that have contributed to this study to ensure that this study is supported by the MDT to allow other researchers to further develop other findings that this study did not reveal. 
There have been several research studies conducted on social media of students from rural areas. Lau and Lee (2018) have found that students make use of social media to get information from the Internet to utilise for academic purposes and communicate with lecturers via email. In contrast to Internet usage, SNSs that are used in the classroom can also distract students and cause them to neglect important activities (Yang et al. 2016).

\section{Industry implications}

The main findings of this research study could provide important information to policymakers, such as advertisers, to build a profitable marketing relationship with younger users, such as students, as SNSs have become endemic in their lives (Omar et al. 2016). Social media advertising should offer precise location-based targeting and data-driven user profiling, segmenting the target market according to preferences, likes and hobbies, through data mining and analytical interpretation of results as these are attributes that are not offered by traditional media. Also, designing a personalised advertisement based on a subscriber's profile and preferences is now a conceivable marketing tool (Amoroso \& Lim 2017).

\section{Limitations and suggestions for future research}

The sample size was relatively small, with only 289 respondents completing the questionnaire. Only one university was included in the study that can limit the generalisability of the research.

The scales used in the study were adapted from studies outside South Africa that could also be a limitation to the study as there may be important factors that were not included in the South African context. Lastly, the research made use of a quantitative research approach, which meant that conclusions were made based on numerical data. If the research had followed both a qualitative and a quantitative approach, the findings could be more in-depth and provide a richer overview of the problem.

Because the research study followed a quantitative research approach, future research should follow a qualitative research approach to gain more in-depth insight into the problem. This research collected data only from rural students from one university. Future research should include students from other rural and urban universities to provide a comparative sample. Lastly, the scales should be tested in the South African context to develop specific scales that are relevant to the country.

\section{Acknowledgements}

The authors acknowledge the support of the Govan Mbeki Research Development Centre and the Research Niche Area within the Faculty of Management and Commerce at the University of Fort Hare.

\section{Competing interests}

The authors declare that they have no financial or personal relationships that may have inappropriately influenced them in writing this article.

\section{Author's contributions}

Z.V.R. and W.C. were responsible for the conceptualisation of the project, while L.C. was responsible for the preparation of the article. Z.V.R. was responsible for the data collection and transcription. L.C. was responsible for data analysis. W.C. was responsible for literature review of the article.

\section{Funding}

This research received no specific grant from any funding agency in the public, commercial or not-for-profit sectors.

\section{Data availability statement}

Data are available upon request.

\section{Disclaimer}

The views and opinions expressed in this article are those of the authors and do not necessarily reflect the official policy or position of any affiliated agency of the authors.

\section{References}

Ajzen, I. \& Fishbein, M., 1981, Understanding attitude and predicting social behaviour, Prentice Hall, Englewood Cliffs, NJ.

Alalwan, A.A., 2018, 'Investigating the impact of social media advertising features on customer purchase intention', International Journal of Information Management 42, 65-77.

Alalwan, A.A., Rana, N.P., Dwivedi, Y.K. \& Algharabat, R., 2017, 'Social media in marketing: A review and analysis of the existing literature', Telematics and Informatics 34(7), 1177-1190. https://doi.org/10.1016/j.tele.2017.05.008

Aleassa, M., Perason, J.M. \& McClurg, S., 2011, 'Investigating software interventions: Comments on hobbies and Sutton', Journal of Business Ethics 98(4), 663-676.

Amoroso, Z. \& Lim, R., 2017, 'The mediating effects of habit on continuance intention', International Journal of Information Management 37(6), 693-702. https://doi. org/10.1016/j.ijinfomgt.2017.05.003

Ashraf, A.R., Thongpapani, N. \& Spyropoulou, S., 2016, 'The connection and disconnection between e-commerce business and their customer: Exploring the role of engagement, perceived usefulness, and perceived ease of use', Electronic Commerce Research and Applications 20(2016), 69-80. https://doi.org/10.1016/j. Commerce Research
elerap.2016.10.001

Bailey, A.A., Bonified, C.M. \& Arias, A., 2018, 'Social media use by young Latin American consumers: An explanation', Journal of Retailing and Consumer Services 43(C), 10-19. https://doi.org/10.1016/j.jretconser.2018.02.003

Beadnell, B., Baker, S.A., Gillmore, M.R., Morrison, D.M., Huang, B. \& Stielstra, S., 2008 'The theory of reasons action and the role of external factors on the heterosexual men's monogamy and condom use', Journal of Applied Social Psychology 38(1) 97-134. https://doi.org/10.1111/j.1559-1816.2008.00298.x

Cao, X., Masood, A., Wu, Y., Xie, X., Wang, X., Zhao, F. et al., 2018, 'Excessive use of mobile social networking sites and poor academic performance: Antecedents and consequences from stressor-strain-outcome perspective', Computers in Human Behavior 85, 163-174. https://doi.org/10.1016/j.chb.2018.03.023

Carillo, K. Scornavacca, E. \& Za, S., 2017, 'The role of media dependency in predicting continuance intention to use ubiquitous media systems', Information \& Management 54(3), 317-335. https://doi.org/10.1016/j.im.2016.09.002

Das, M., 2014, 'Using social networking sites (SNS): Mediating role of self-disclosure and effect on well-being', Irish Medical Journal 6(2), 30-38.

Farhangpour, P. \& Matendawafa, A., 2016, 'The impact of social network sites on the academic behaviour and written language use of university students', Journal of Educational Studies 15(2), 20-38.

Fishbein, M. \& Ajzen, I., 2005, 'Theory-based behaviour change interventions: Comments on hobbies and Sutton', Journal of Health Psychology 10(1), 27-31. https://doi.org/10.1177/1359105305048552

Giunchiglia, F., Zeni, M., Gobbi, E., Bignotti, E. \& Bison, I., 2017, 'Mobile social media usage and academic performance', Computers in Human Behaviour 82, 177-185. https://doi.org/10.1016/j.chb.2017.12.041 
Griffiths, M., 2005, 'A 'components' model of addiction within a biopsychosocial framework', Journal of Substance Use 10(4), 191-197. http://doi.org/10.1080/ 14659890500114359

Hadija, Z., Barnes, S.B. \& Hair, N., 2012, 'Why we ignore social networking advertising', Qualitative Market Research and Public Health, An International Journal 15(1) 19-32. https://doi.org/10.1108/13522751211191973

Hajarian, M., Bastanfard, A., Mohammadzaden, J. \& Khalilian, M., 2017, 'Introducing fuzzy like in social networks and its effects on advertising profits and human behaviour', Computers in Human Behaviour 77(C), 282-293. https://doi.org/ 10.1016/j.chb.2017.08.046

Hamid, A.A., Razak, F.Z.A., Bakar, A.A. \& Abdullah, W., 2016, 'The effects of perceived usefulness and perceived ease of use on continuance intention to use e-government', Procedia Economics and Finance 35(2016), 664-649.

Hansen, J.M., Saridakas, G. \& Benson, V., 2017, 'Risk, trust and the interaction of perceived ease of use and behavioural control in predicting consumers use of socia media for transactions', Computers in Human Behaviour 80(20158), 197-206. https://doi.org/10.1016/j.chb.2017.11.010

Hsiao, C.H., Chang, J.J. \& Tang, K.Y., 2016, 'Exploring the influential factors in continuance usage of mobile social Apps: Satisfaction, habit and customer value perspective', Telematics and Informatics 33(2), 342-355. https://doi.org/10.1016/j. tele.2015.08.014

Hung, S., Tsai, J. \& Chuo, S., 2016, 'Decomposing perceived playfulness: A contextual examination of two social networking sites', Information \& Management 53(6), 698-716. https://doi.org/10.1016/j.im.2016.02.005

Kuss, D.J. \& Griffiths, M.D., 2011, 'Online social networking and addiction - A review of the psychological literature', International Journal of Environmental Research and Public Health 8(9), 3528-3552. https://doi.org/10.3390/ijerph 8093528

Kyeyune, A.P., 2010, 'The interpretation and use of mixed methods research within programme evaluation practice', Master's thesis, The University of Stellenbosch, Stellenbosch, South Africa.

Lau, H.T. \& Lee, R., 2018, 'Ethnic media advertising effectiveness, influence and implications', Australian Marketing Journal 26(3), 1-5. https://doi.org/10.1016/j. ausmj.2018.05.014

Lee, J. \& Choi, Y., 2018, 'Informed public against false rumour in the social media era: Focusing on social media dependency', Telematics and Management 35(5), 1071-1081. https://doi.org/10.1016/j.tele.2017.12.017

Li, X., 2014, 'Perceived channel efficiency and motivation and orientation seeking as predictors of media dependency', Telematics and Infomatics 31(4), 628-639.

Lin, C. \& Wang, H., 2017, 'Understanding users switching intentions and switching behaviour on social networking sites', Aslib Journal of Information Management 69(2), 201-214. https://doi.org/10.1108/AJIM-08-2016-0127

Lin, Y., 2008, Media dependency theory, Sage, London.

Liu, C. \& Ma, J., 2018, 'Development and validation of the Chinese social media addiction scale', Personality and Individual Differences 134(2018), 55-59. http:// doi.org/10.1016/j.paid.2018.05.046

Marino, C., Gini, G., Vieno, A. \& Spada, M.M., 2018, 'A comprehensive meta-analysis on problematic Facebook use', Computers in Human Behaviour 83(2018), 262-277. http://doi.org/10.1016/j.chb.2018.02.009

Matikiti, R., Mpinganjira, M. \& Roberts-Lombard, M., 2017, 'Social media in tourism Establishing factors influencing attitudes towards the usage of social networking sites for the trip organisation', Acta Commercii 17(1), 1-13. https://doi.org/ 10.4102/ac.v17i1.396

Meier, A., Reinecke, L. \& Meltzer, C.E., 2016, 'Facebocration? Predictors of using Facebook for procrastination and its effects on students well-being', Computers in Human Behaviour 110(2016), 16-34.

Moqbel, M. \& Kock, N., 2017, 'Unveiling the dark side of social networking sites: Personal and work-related consequences of social networking site addiction', Information \& Management 55(2017), 109-119. https://doi.org/10.1016/j.im. 2017.05.001
Muller, K.W., Dreier, M., Beutel, M.E., Duren, E., Girait, S. \& Wolfling, K., 2015, 'A hidden type of internet addiction? Intense and addictive use of social networking sites in adolescents', Computers in Human Behaviour 55(Part A), 172-176. https://doi. adolescents', Computers in Humar
org/10.1016/j.chb.2015.09.007

Muwanga-Zake, O. \& Herselman, M., 2017, 'An investigation into possibilities for implementation of a virtual community of practice delivered via a mobile social network for rural community media in the Eastern Cape, South Africa', South African Journal of Information Management 19(1), 1-10. https://doi.org/10.4102/ sajim.v19i1.730

Nunnally, J.C., 1978, Psychometric theory, 2nd edn., McGraw Hill, New York.

Ohajionu, U.C. \& Matthews, S., 2015, 'Advertising on social media and benefits to brands', Journal of Social Sciences and Humanities 10(2), 335-351. https://doi. org/10.1080/02650487.2015.1021898

Omar, M.K., Dahalan, N.A. \& Yusoff, Y.H.M., 2016, 'Social media usage, perceived team-efficacy and knowledge sharing behaviour among employees of an oil and gas organisation in Malaysia', Procedia Economics and Finance 37, 309-316. https://doi.org/10.1016/S2212-5671(16)30130-7

Osatuyi, B. \& Turel, O., 2018, 'Tug of war between social self-regulation and habit: Explaining the experience of momentary social media addiction symptoms', Computers in Human Behaviour 85, 95-105. https://doi.org/10.1016/j.chb. 2018.03.037

Pallant, J., 2016, SPSS survival manual, McGraw-Hill Education, Berkshire.

Parveen, F., Jaafar, N.I. \& Anin, S., 2014, 'Social media usage and organisational performance: Reflections of Malaysian social media managers', Telematics and Informatics 32(1), 67-78. https://doi.org/10.1016/j.tele.2014.03.001

Saade, R.G. \& Kira, D., 2017, 'Mediating the impact of technology usage on perceived ease of use by anxiety', Computers \& Education 49(4), 1189-1204. https://doi. org/10.1016/j.compedu.2006.01.009

Sanne, P.N.C. \& Wiese, M., 2018, 'The theory of planned behaviour and user engagement applied to Facebook advertising', South African Journal of Information Management 20(1), 1-10.

Shareef, M.A., Mukerji, B., Dwivedi, Y.K., Rana, N.P. \& Islam, R., 2017, 'Social media marketing: Comparative effect of advertisement sources', Journal of Retailing and Consumer Services 4(C), 66-72. https://doi.org/10.1016/j.jretconser.2017.11.001

Shava, H. \& Chinyamurindi, W.T., 2018, 'Determinants of social media usage among a sample of rural South African youth', South Africa Journal of Information Management 20(1), 1-8. https://doi.org/10.4102/sajim.v20i1.827

Southey, G., 2011, 'The theories of reasoned action and planned behaviour applied to business decisions: A selective Annotated Bibliography', Journal of New Business Ideas \& Trends 9(1), 43-50.

Tlou, E.R., 2009, 'The application of the theories of reasoned action and planned behaviour to a workplace HIV/ AIDS health promotion programme', Doctor of Philosophy thesis, University of South Africa, Pretoria, South Africa.

Trafimow, D. \& Lench, H., 2015, 'The sufficiency assumption of the reasoned approach to action', Cognet Psychology 2(1), 1-17. https://doi.org/10.1080/23311908.2015. 1014239

Wood, W. \& Runger, D., 2015, 'Psychology of habit', The Annual Review of Psychology 67, 11.1-11.26

Yahia, I.B., Al-Neama, N. \& Kerabache, L., 2018, 'Investigating the drivers for social commerce in social media platforms: Importance of trust, social support and the platform perceived usage', Journal of Retailing and Consumer Services 41(C) 11-19. https://doi.org/10.1016/j.jretconser.2017.10.021

Yang, S., Wang, B. \& Lee, Y., 2016, 'Exploring the dual outcomes of mobile social networking service enjoyment: The roles of social self-efficacy and habit', Computers in Human Behaviour 64(2018), 486-496. https://doi.org/10.1016/j chb.2016.07.010

Yu, Q., Zhang, L., Wu, S., Guo, Y., Jin, S. \& Sun, Y., 2017, 'The influence of juvenile preference for online social interaction on problematic internet use: The moderating effect of sibling condition and the moderated moderating effect of age
cohort', Computers in Human Behaviour 68, 345-351. https://doi.org/10.1016/j. chb.2016.11.026 